ARTIGO

\title{
PRODUÇÃO CIENTÍFICA NO CONTEXTO EDUCACIONAL DOS POVOS DO CAMPO, ÁGUAS E FLORESTAS NO BRASIL
}

\author{
SCIENTIFIC PRODUCTION IN THE EDUCATIONAL CONTEXT OF COUNTRYSIDE \\ PEOPLES, WATERS AND FORESTS IN BRAZIL
}

\section{LA PRODUCCIÓN CIENTÍFICA EN EL CONTEXTO EDUCATIVO DE LOS PUEBLOS}

\author{
RURALES, LAS AGUAS Y LOS BOSQUES DEL BRASIL
}

\author{
Adalberto Penha de Paula \\ Universidade Federal do Paraná - Brasil \\ Leilah Santiago Bufrem \\ Universidade Federal do Paraná - Brasil
}

\begin{abstract}
Resumo: Considerando a realidade das comunidades tradicionais do litoral do Paraná e a relação entre Educação do Campo e Território, apresenta discussões sobre os significados da escola do campo a partir do levantamento de pesquisas. Objetiva colaborar com um campo de investigação da área da educação, isto é, a Educação do Campo, articulando a produção do conhecimento registrada, portanto validada pelas instâncias acadêmicas, com as dimensões que a constituem. Procede com o levantamento de informações na base de dados do Catálogo de Teses e Dissertações da Coordenação de Aperfeiçoamento de Pessoal de Nível Superior (CAPES), apresenta e dialoga com os principais trabalhos encontrados através do uso de descritores. Deste modo, observa que o diálogo com os trabalhos identificados contribui significativamente com novas compreensões e indica que as pesquisas avançam para além da educação, visto que em sua maioria apresentam análises relacionadas com outros aspectos e segmentos da sociedade. Conclui que as revisões bibliográficas são estratégia necessária para verificar o conhecimento produzido em determinada na área de pesquisa e que é urgente a articulação entre os sujeitos do campo, das águas e das florestas, além de outras populações que se encontram à margem para o fortalecimento das comunidades e territórios na luta e garantia dos seus diretos.
\end{abstract}

Palavras chave: Produção do Conhecimento. Educação do Campo. Escola do campo.

\begin{abstract}
Considering the reality of traditional communities on the coast of Paraná and the relationship between Countryside Education and Territory, it presents discussions about the meanings of rural schools based on research surveys. It aims to collaborate with a field of research in the field of education, the Countryside Education, articulating the production of registered knowledge, therefore validated by academic bodies, with the dimensions that constitute it. Proceed with the collection of information in the database of the Catalog of Theses and Dissertations of the Coordination for the Improvement of Higher Education Personnel (CAPES), presents and dialogues with the main works found through the use of descriptors. Thus, it observes that the dialogue with the identified works contributes significantly to new understandings and indicates that the research go beyond education, since most of them present
\end{abstract}


analyzes related to other aspects and segments of society. It concludes that bibliographic reviews are a necessary strategy to verify the knowledge produced in a given research area and that it is urgent to articulate the subjects of the field, the waters and the forests, in addition to other populations that are on the margins, to strengthen the communities and territories in the struggle and guarantee of their rights.

Keywords: Knowledge Production. Countryside Education. Countryside school.

Resumen: Considerando la realidad de las comunidades tradicionales de la costa de Paraná y la relación entre Educación Campestre y Territorio, presenta discusiones sobre los significados de las escuelas rurales a partir de encuestas de investigación. Tiene como objetivo colaborar con un campo de investigación en el campo de la educación, la Educación del Campo, articulando la producción de conocimiento registrado, por tanto validado por cuerpos académicos, con las dimensiones que lo constituyen. Continuar con la recogida de información en la base de datos del Catálogo de Tesis y Disertaciones de la Coordinación para la Perfeccionamiento del Personal de Educación Superior (CAPES), presenta y dialoga con los principales trabajos encontrados mediante el uso de descriptores. Así, observa que el diálogo con las obras identificadas contribuye significativamente a nuevos entendimientos e indica que las investigaciones van más allá de la educación, ya que la mayoría de ellas presentan análisis relacionados con otros aspectos y segmentos de la sociedad. Se concluye que las revisiones bibliográficas son una estrategia necesaria para verificar el conocimiento producido en un área de investigación determinada y que es urgente articular los temas del campo, las aguas y los bosques, además de otras poblaciones que se encuentran al margen, para fortalecer las comunidades y territorios en la lucha y garantía de sus derechos.

Palabras clave: Producción del conocimiento. Educación en el campo. Escuela del campo.

\section{Introdução}

Os estudos em Educação do Campo ${ }^{1}$ vêm ocupando, historicamente, seu espaço nas universidades brasileiras, indicando a sua importância no avanço do conhecimento. Conforme Souza (2016), cinco fatores favorecem esse crescimento, a saber: a) a participação do MST na sociedade brasileira e suas demandas educacionais; b) o diálogo entre movimento social e sociedade política; c) a ampliação dos grupos de pesquisa dedicados aos estudos da realidade educacional do campo no Brasil; d) a existência de programas governamentais como o Pronera e o Procampo; e) o conjunto de diretrizes, resoluções e decreto presidencial que positivam a Educação do Campo como política pública.

Neste cenário, o artigo apresentado é parte das discussões realizadas na pesquisa de doutorado, intitulada "Relações entre Educação do Campo e o Território: significados da escola da/na ilha para uma comunidade tradicional de Guaraqueçaba no litoral do Paraná”, denominada neste trabalho de pesquisa matriz, cujo objetivo foi compreender o significado que a educação e a escola do campo da/na ilha têm para as comunidades do litoral paranaense na

1 Ver SOUZA, Maria Antônia de. Educação e movimentos sociais do campo: a produção do conhecimento no período de 1987 a 2015. Curitiba: Editora UFPR, 2016. 
relação com o território. Para essa compreensão, utilizou-se do enfoque de pesquisa de natureza etnográfica na educação e do levantamento e análise da literatura sobre o tema da pesquisa com a proposta de contribuir com os estudos nesta área, tema recente de investigação acadêmica, instigante de novas pesquisas.

Assim, neste artigo, pretende-se oferecer um panorama das construções teóricas registradas como produção científica, tanto em termos de seu significado para o desenvolvimento do campo de conhecimento, quanto de suas vertentes temáticas e concentrações de interesses, selecionando-se um recorte da produção científica registrada. Desse modo, almeja-se contribuir com o conhecimento sobre os territórios das populações representativos da diversidade de comunidades do campo, águas e florestas, mais especificamente sobre a educação.

No sentido de ampliar e aprofundar as reflexões sobre a Educação do Campo, inserida no cenário mais amplo e complexo da educação brasileira, compreende-se que esta temática de investigação vem ocupando seu lugar nas pesquisas acadêmicas dos programas de pósgraduação, em nível stricto sensu, ainda de forma tímida, segundo enfatiza Souza (2016). Nesta perspectiva de contribuir com as investigações científicas em Educação do Campo, principalmente a partir da escola do campo e seu território, tornam-se oportunas pesquisas que busquem fortalecer o conhecimento produzido a partir da realidade do campo, das águas e das florestas. Entende-se, desse modo, que o conhecimento no seu processo de produção requer que se ultrapasse o nível da experiência imediata em busca das relações complexas que se constroem na realidade. Portanto, o conhecimento científico é considerado "[...] um produto histórico e social inserido na sociedade capitalista contemporânea e marcado pelos intensos conflitos nela presentes.” (MOLINA; ANTUNES-ROCHA; MARTINS, 2019, p. 5).

As premissas aqui analisadas convergem para a proposta deste trabalho, no sentido de colaborar com o campo de investigação, articulando a produção do conhecimento registrada, portanto validada pelas instâncias acadêmicas, com as dimensões constituintes da Educação do Campo. Metodologicamente, realizou-se levantamento de pesquisas na base de dados do Catálogo de Teses e Dissertações da Coordenação de Aperfeiçoamento de Pessoal de Nível Superior (CAPES), com recorte temporal no período entre 1998 e 2019.

No levantamento inicial dos trabalhos, utilizaram-se dos descritores: "escola do campo", "escola no campo", "escola rural", "escola da ilha", "escola das ilhas", "escola na ilha", "escola nas ilhas", "escola em ilha", "educação ribeirinha", "escola ribeirinha" e "Guaraqueçaba", destes localizou-se 53 pesquisas, sendo 10 oriundas de pesquisa de doutorado e 43 de mestrado. A fim de adensar este levantamento no diálogo como campo empírico da 
pesquisa matriz, identificou-se outras seis pesquisas, duas que investigaram as Casas Familiares do Mar ambas de doutorado e quatro pesquisas realizadas no contexto do litoral paranaense, dois de doutorado e dois de mestrado.

Justifica-se este trabalho por apresentar as investigações acadêmicas que contribuíram com a pesquisa matriz, a fim de identificar a produção científica de um determinado domínio do conhecimento, neste caso, a Educação do Campo. Além disso, apresenta-se um panorama do que vem sendo discutido nos diferentes territórios, no que se refere à educação e à escola do campo na relação com as demais questões relacionadas aos povos do campo, das águas e das florestas, isto é, a cultura, a identidade, os conhecimentos, os conflitos territoriais e ambientais, visando fortalecer o conhecimento sobre a Educação do Campo, bem como a existência e reexistência das comunidades.

Este texto, além desta introdução, organiza as discussões a partir dos seguintes tópicos: Revisão de literatura: Educação do Campo e os povos do campo, águas e florestas; Percurso metodológico: levantamento e apresentação das produções acadêmicas; e Resultados e análises: diálogos com as pesquisas. E, por fim, as considerações finais evidenciam as contribuições da revisão bibliográfica para a pesquisa, a importância da escola nas comunidades do campo, das águas e das florestas, para além do seu papel de escolarização. Enfatiza-se a necessidade da continuidade de novas pesquisas, na produção de conhecimentos a partir da Educação do Campo. E destaca-se que, para o fortalecimento destes povos, faz-se urgente o diálogo e articulação entre os sujeitos da terra e do mar, bem como das periferias, das cidades, ou seja, os povos que estão à margem, a partir da tomada de consciência das suas realidades.

\section{Revisão de literatura: Educação do Campo e os povos do campo, águas e florestas}

O ato da pesquisa exige a exploração inicial do que está sendo produzido no campo de inserção do investigador, decorrendo que as revisões de literatura são parte essencial no processo de produção da ciência, de modo que se possa conhecer o que já foi produzido em determinado campo de pesquisa, pois o conhecimento, assim como a vida, não é imutável, mas sim dinâmico e dialético. Neste sentido, compreende-se que o conhecimento não é estático, linear, a-histórico e sem relação com o contexto, mas sim um processo histórico, político, cultural e social. É produzido em um movimento dialético entre a materialidade da vida e da sociedade onde é elaborado, "[...] é realizado, portanto, sob um ponto de vista relacional, isso é, pela consideração dos fatos em sua relação uns com os outros; [...] de como entre si se entrosam nas duas dimensões da sucessão, transformação e simultaneidade [...]" (BUFREM, 2016, p. 100-101). 
Assim, com o objetivo de buscar informações sobre as produções acadêmicas constituintes deste movimento mais amplo de produção do conhecimento, enquanto atividade cognoscente na Educação do Campo, foram realizadas pesquisas em uma base de dados ampla e reconhecida no meio acadêmico, isto é, no Catálogo de Teses e Dissertações da Coordenação de Aperfeiçoamento de Pessoal de Nível Superior (CAPES). Foram mapeadas as pesquisas com aderência ao tema Educação do Campo, cujos resultados passam a integrar o objeto das discussões deste trabalho.

A revisão de literatura apresentada não tem o objetivo de se constituir em análise exaustiva e aprofundada das pesquisas, mas foi desenvolvida para indicar elementos a fim de compreender a Educação e Escola do Campo na relação com o território, a cultura, a comunidade, o modo de vida, bem como os caminhos que foram delineados na pesquisa originária deste texto. Optou-se por apresentar uma revisão reproduzindo uma síntese dos resumos das principais teses e dissertações selecionadas, de modo a situar as principais características de cada pesquisa. Reconhecido o estudo de Souza (2016), um levantamento da produção do conhecimento em Educação do Campo, a partir de uma pesquisa na literatura pertinente, priorizando a análise do conteúdo de teses e dissertações produzidas no período de 1987 a 2015, o trabalho aqui relatado parte de um recorte temporal mais recente.

Ressalta-se que o recorte temporal para a pesquisa foi o período entre 1998 e 2019, escolha que se justifica em virtude do marco histórico para a Educação do Campo no Brasil, com a realização da I Conferência Nacional: Por uma Educação Básica do Campo no ano de 1998 em Goiânia. Entende-se que esta conferência é um marco público da Educação do Campo na disputa pelos espaços institucionais como é o caso da escola e da universidade pública, como se evidencia no texto base, "Acesso de toda a população a uma escola pública, gratuita e de qualidade, desde a educação infantil até, pelo menos, o ensino médio, já colocando no horizonte a demanda do ensino superior." (KOLLING; NERY; MOLINA, 1999, p. 59).

Enquanto parâmetro para o levantamento na base de dados escolhida definiu-se a busca somente por pesquisas que dialogassem com as seguintes grandes áreas do conhecimento: Ciências Humanas, Ciências Sociais, Ciências Agrárias, Ciências Exatas e da Terra. Com o levantamento inicial dos trabalhos, cuja estratégia de busca partiu dos descritores: "escola do campo", "escola no campo", "escola rural", "escola da ilha", "escola das ilhas", "escola na ilha", "escola nas ilhas", "escola em ilha”, localizaram-se 531 trabalhos entre teses e dissertações. A seguir foram localizados os trabalhos cujos títulos têm afinidades com temas transversais a este trabalho, a saber: território, comunidade, significado da escola, cultura, identidade, conhecimentos e saberes tradicionais, resistência, comunidades tradicionais e 
conflitos territoriais. Identificaram-se, então, 41 trabalhos com aderência à pesquisa, sendo sete teses e 34 dissertações.

$\mathrm{Na}$ continuidade do levantamento e considerando o território das "águas" enquanto lugar da materialidade da vida e balizando-se em Cunha (2000, p.19), a qual afirma que, “[...] No universo da pesca é possível evidenciar um conjunto de significados simbólicos impressos à água pelo pescador artesanal [...]”. A água apresenta muitos significados, água não só representa a virtude, a beleza, a liberdade; é a fonte de criação e de destruição, vida e morte (CUNHA, 2000). Optou-se em utilizar os descritores "Educação Ribeirinha" e "Escola Ribeirinha", visto que a água é o elemento comum, que une a vida das populações das ilhas (do mar) e os ribeirinhos (o rio). Foi possível localizar 26 trabalhos entre teses e dissertações, dos quais nove pesquisas tiveram aderência ao trabalho, sendo duas teses e sete dissertações.

Buscando conhecer os trabalhos realizados, geograficamente, no campo empírico de inserção, utilizou-se o descritor "Guaraqueçaba". Esta estratégia apresentou como resultado 67 pesquisas, das quais uma tese e duas dissertações demonstraram aderência à pesquisa matriz. Além delas, outras seis pesquisas foram encontradas, sendo duas sobre as Casas Familiares do Mar, ambas de doutorado e quatro pesquisas realizadas no contexto do litoral, sendo duas de doutorado e duas de mestrado.

Na sequência apresentam-se, sinteticamente, as principais pesquisas acadêmicas com aderência com a pesquisa matriz. De modo geral, indicam a importância de investigações científicas no campo educacional junto às populações tradicionais, dialogando com a realidade dos povos do campo, das águas e das florestas. Com respaldo nas pesquisas existentes, nas teorias relacionadas a questões de interesse para este trabalho, nos temas e evidências destacados e em diversos estágios de estudo, relatados nas fontes pesquisadas, foram reforçados pontos de partida para esta criação intelectual.

\section{Percurso metodológico: levantamento e apresentação das produções acadêmicas}

Conforme descrito, realizaram-se pesquisas na base de dados do Catálogo de Teses e Dissertações da Coordenação de Aperfeiçoamento de Pessoal de Nível Superior (CAPES), onde foram encontrados, para o devido mapeamento e análise, os trabalhos com aderência a esta pesquisa.

Os trabalhos expostos nesta seção, conforme Quadro 1, foram produzidos em diferentes programas de pós-graduação, áreas do conhecimento e instituições, somando 59 pesquisas, distinguindo-se em pesquisas de Doutorado (D) e de Mestrado (M). 
Quadro 1 - Levantamento quantitativo dos trabalhos selecionados para a revisão de literatura

\begin{tabular}{|c|c|c|c|}
\hline \multirow{2}{*}{$\begin{array}{c}\text { Localizadas através de pesquisa com os seguintes } \\
\text { descritores }\end{array}$} & \multicolumn{3}{|c|}{ Número de trabalhos } \\
\hline & $\mathbf{D}$ & $\mathbf{M}$ & Total \\
\hline "Escola do Campo" & 04 & 14 & 18 \\
\hline "Escola no Campo" & 00 & 07 & 07 \\
\hline "Escola Rural" & 02 & 11 & 13 \\
\hline "Escolas da Ilha" & 0 & 01 & 01 \\
\hline "Escola das Ilhas" & 01 & 01 & 02 \\
\hline "Escolas das Ilhas" & 0 & 0 & 0 \\
\hline "Escola na Ilha" & 0 & 0 & 0 \\
\hline "Escola nas Ilhas" & 0 & 0 & 0 \\
\hline "Escola em Ilha" & 0 & 0 & 0 \\
\hline "Escola em Ilhas" & 0 & 0 & 0 \\
\hline "Educação Ribeirinha" & 0 & 01 & 01 \\
\hline "Escola Ribeirinha" & 02 & 06 & 08 \\
\hline "Guaraqueçaba" & 01 & 02 & 03 \\
\hline Total de trabalhos & 10 & 43 & 53 \\
\hline \multirow{2}{*}{$\begin{array}{l}\text { Localizadas através de leituras e não encontradas com } \\
\text { os descritores selecionados. }\end{array}$} & \multicolumn{3}{|c|}{ Número de trabalhos } \\
\hline & $\mathbf{D}$ & $\mathbf{M}$ & Total \\
\hline Casa Familiar do Mar & 02 & 0 & 02 \\
\hline Contexto do Litoral & 02 & 02 & 04 \\
\hline Total de trabalhos & 04 & $\mathbf{0 2}$ & 06 \\
\hline $\begin{array}{l}\text { Total de pesquisas selecionadas para a revisão de } \\
\text { literatura a partir dos descritores e leituras. }\end{array}$ & 14 & 45 & 59 \\
\hline
\end{tabular}
literatura a partir dos descritores e leituras. FONTE: Paula (2019).

Outro dado relevante, conforme o Gráfico 1, é que após 2007 houve crescimento significativo de pesquisas relacionadas à Educação do Campo, evidência indicativa do reconhecimento por parte dos pesquisadores dessas universidades, da necessidade de investigações acadêmicas neste campo específico de pesquisa. Um dos elementos que justificam este aumento de trabalhos pode ser o conjunto de ações representativas dos avanços das políticas públicas da Educação do Campo, no período, principalmente referentes à ampliação do acesso ao ensino superior.

Gráfico 1 - Pesquisas em Educação do Campo (1992-2018)

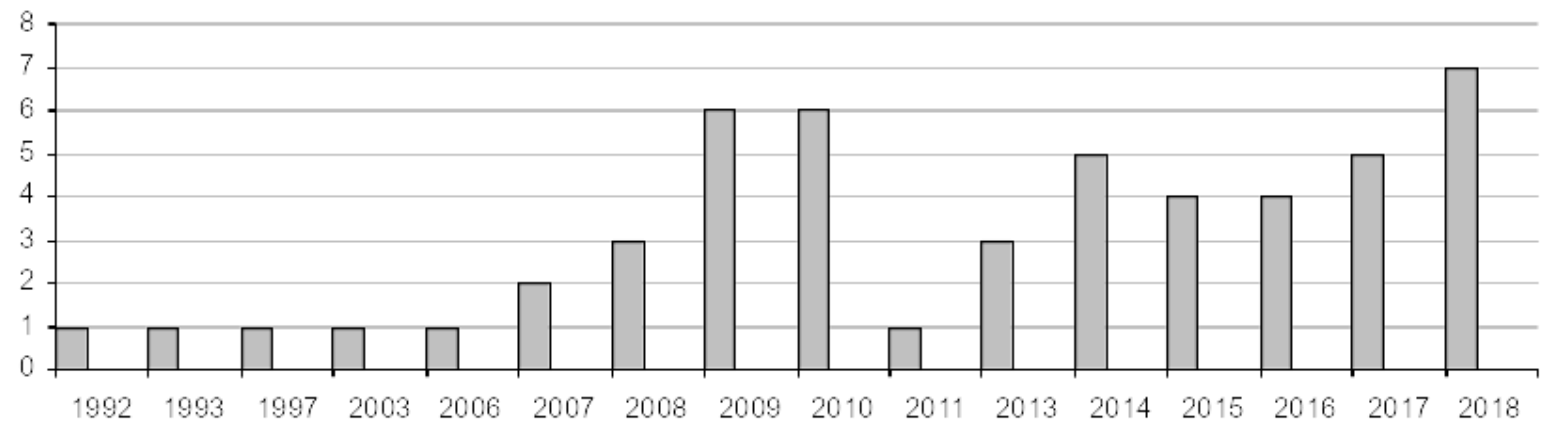

FONTE: Paula (2019). 
Evidencia-se também, conforme levantamento, a diversidade de áreas do conhecimento dos programas de pós-graduação onde foram realizadas as pesquisas, o que demonstra a capilaridade da Educação do Campo, enquanto objeto de pesquisa a partir de diferentes enfoques e olhares, porém destaca-se a área da Educação.

A fim de apresentar as pesquisas identificadas na base de dados buscou-se, através de uma análise seletiva dos resumos das pesquisas, expressar os principais elementos dos referidos trabalhos, os quais são apresentados e organizados a seguir a partir dos seus descritores de busca e ano da pesquisa. Estes estudos permitiram conhecer as problemáticas tratadas e as demandas de novas pesquisas.

Na sequência expõem-se quadros com informações detalhadas referentes às pesquisas selecionadas, com as seguintes informações: Autor(a), Ano, Instituição de Ensino Superior, Programa de Pós-Graduação. Ressalta-se que somente serão descritas as principais pesquisas localizadas, dentre aquelas aderentes com a pesquisa matriz.

Primeiramente, apresentam-se as principais pesquisas oriundas do descritor "Escola do Campo", foram selecionados 18 trabalhos entre quatro teses e 14 dissertações.

Quadro 2 - Pesquisas localizadas a partir do descritor "Escola do Campo" que tem aderência com a pesquisa matriz

\begin{tabular}{|c|c|c|}
\hline Autoras(es) & Instituições & Programas de Pós-Graduação \\
\hline Mendes (2009; 2017), & & \\
Moura (2009), Pereira (2003), & & \\
Klein (2013), Melo (2014), & UFPR, UFMS, & Educação, Geografia, Educação \\
Silva (2014a), Silva (2014b), & UNIOESTE,UFES, & nas Ciências, Desenvolvimento \\
Gugelmin (2014), Souza & UFPI,UCDB,UFMT, & Territorial na América Latina e \\
(2015), Santos (2015), Nahine & UNEMAT, UFGD, UNIJUÍ, & Caribe. \\
(2017), Ziech (2017), Lima & UNESP, UFMG, UFAM, UFS. & \\
(2017), Silva (2018), Uchoa & & \\
(2018), Vieira (2018),Correia & & \\
(2018). & & \\
\hline
\end{tabular}

FONTE: Os autores (2020).

O trabalho de Mendes (2009) identifica o significado que a Escola do Campo tem para os professores e professoras, considerando os elementos que constituem a especificidade destas escolas. A pesquisa de Pereira (2013) evidencia a importância do Movimento Nacional por uma Educação do Campo, e como ele contribuiu com a conquista de políticas públicas educacionais, as quais valorizam a identidade e a cultura das populações do campo. Busca compreender como a Educação do Campo se territorializou nas escolas do campo articulada com as organizações populares, demonstrou que a Educação do Campo e a escola são um movimento que busca mudanças na sociedade e no Estado.

O trabalho de Silva (2014a) analisa as práticas mono/multi/interculturais presentes no currículo de uma escola do campo, articulando-as com a produção das identidades/diferenças 
dos/as alunos/as. Aponta que o currículo da escola ainda desenvolve práticas monoculturais, embora em alguns momentos recorra a práticas inter/multiculturais. Mendes (2017) ao desenvolver sua a pesquisa, objetivou contribuir para a compreensão dos significados da especificidade da Educação do Campo e da escola do campo que circulam na cultura escolar como resultado da produção de diferentes sujeitos sociais. Defende a tese de que os argumentos para justificar a especificidade da Educação e da Escola do Campo sofreram transformações expressivas nas duas últimas décadas.

Por fim, o trabalho de Vieira (2018) busca compreender as relações que os jovens de uma escola do campo estabelecem com as demandas por especificidades em sua escolarização, nas condições específicas de ser jovem em uma situação particular - alunos de escola de assentamento da reforma agrária. Os resultados colocam em evidência elementos da cultura dos jovens que vivem no campo e trazem seus pontos de vista sobre os significados da escolarização, a presença e as contribuições dos livros para sua formação, e suas expectativas enquanto jovens que vivem a sua condição juvenil.

A seguir apresentam-se as principais pesquisas oriundas do descritor "Escola no Campo", todas em formato de dissertações.

Quadro 3 - Pesquisas localizadas a partir do descritor "Escola no Campo" que tem aderência com a pesquisa matriz

\begin{tabular}{|c|c|c|}
\hline Autoras(es) & Instituições & Programas de Pós-Graduação \\
\hline Rodriguez (2008), Cruz (2013), & UFSC, UFV, & Educação, Economia Doméstica, \\
Rego (2016), Albuquerque & UERR/IFRR, UFPR, & Educação: Teoria e Prática de \\
(2017), Araújo (2017a), Araújo & UEPB, UNEB, & Ensino, Formação de Professores, \\
(2017b), Boito (2017). & UFRGS. & Educação e Diversidade. \\
\hline
\end{tabular}

FONTE: Os autores (2020).

O estudo de Rego (2016), desenvolvido a luz do materialismo histórico-dialético, foi realizado em uma escola pública do campo, tendo como objetivo geral investigar o currículo desenvolvido em uma escola no campo e sua inter-relação com o mundo do trabalho. Aponta alternativas para um trabalho pedagógico voltado para a emancipação e transformação da Escola do Campo. Albuquerque (2017) objetiva com sua pesquisa compreender como o estudante que vive no campo percebe sua escola. Foram realizados estudos de caráter etnográfico com o intuito de captar elementos de sua realidade cotidiana e os conhecimentos adquiridos com suas experiências na e fora da escola, que pudessem contribuir para a formação de sua percepção.

Boito (2017) no seu trabalho objetiva compreender quais especificidades das práticas pedagógicas caracterizam uma escola no campo como do campo. Evidencia ações pedagógicas que favorecem, no contexto pesquisado, uma perspectiva de escola no/do campo, tais como: a reelaboração constante do Projeto Político Pedagógico junto à comunidade; a intensa parceria 
entre família, escola e comunidade; a valorização das "coisas do campo" nas práticas pedagógicas da instituição; e o reconhecimento do brincar, e da ludicidade.

Continuando, apresentam-se as principais pesquisas oriundas do descritor "Escola Rural", sendo 13 trabalhos, duas teses e 11 dissertações.

Quadro 4 - Pesquisas localizadas a partir do descritor "Escola Rural" que tem aderência com a pesquisa matriz

\begin{tabular}{|c|c|c|}
\hline Autoras(es) & Instituições & Programas de Pós-Graduação \\
\hline Queiroz (1992), Rodrigues & & \\
(1993), Oliveira (2003), & & \\
Benfica (2006), Cristo & UFC, UFMG, UFPA, & Educação, Agriculturas \\
(2007), Lima (2008), & PUC-MG, UFPA, UFV, & Amazônicas, Extensão Rural, \\
Silveira (2009), Reis (2009), & UFPEL, UFBA, USP, UNB & Psicologia, Educação e \\
Ferraz (2010), Teodoro & UFAM, UEFS, UNEB. & Contemporaneidade. \\
(2010), Ferreira (2010), & & \\
Lima (2015), Lima (2018). & & \\
\hline
\end{tabular}

FONTE: Os autores (2020).

Rodrigues (1993), cujo objetivo foi compreender o significado da escola para os sujeitos das áreas rurais, tenta captar a influência das condições e da natureza do processo de trabalho na construção desse significado. A pesquisa de Oliveira (2003) discute a execução de um programa governamental em escolas rurais, levanta questões acerca da contribuição de tal programa para a melhoria do processo ensino-aprendizagem dos alunos e alunas e para a mudança das práticas pedagógicas das professoras.

O trabalho de Ferraz (2010) investiga os agenciamentos operados na escola na produção de modos de subjetivação, no contexto de transformações das comunidades ribeirinhas. Aponta a importância que os moradores atribuem à escola, percebida como componente que favorece a melhoria das condições de vida. A escola apresenta-se distante da realidade local, desqualifica o saber tradicional, impondo concepções mercantilizadas e a transmissão de um saber hegemônico. Ferreira (2010) estuda o cotidiano de uma escola rural/ribeirinha na Amazônia, analisando se - e de que forma - a vida, a cultura e o rio entram na escola, identificando como estas temáticas são consideradas e trabalhadas (ou não) no contexto escolar, além de verificar se essa realidade diferenciada é considerada nos processos de formação dos professores.

$\mathrm{Na}$ sequência, apresentam-se as principais pesquisas recuperadas a partir do descritor "Escola da Ilha" e "Escola das Ilhas", sendo três trabalhos, uma tese e duas dissertações, optouse por agregar os descritores em decorrência do baixo número de trabalhos localizados. Os descritores "escolas das ilhas", "escola na ilha", "escola nas ilhas", "escola em ilha" e "escolas em ilhas" não apresentaram resultados de trabalhos que tivessem aderência à pesquisa matriz. 
Quadro 5 - Pesquisas localizadas a partir do descritor "Escola da Ilha", "Escola das Ilhas" que tem aderência com a pesquisa matriz

\begin{tabular}{|c|c|c|}
\hline Autoras(es) & Instituições & Programas de Pós-Graduação \\
\hline $\begin{array}{c}\text { Freitas (1997), Oliveira } \\
\text { (2017), Farias (2018). }\end{array}$ & UNICAMP, UFPR, UFG. & $\begin{array}{c}\text { Educação, Educação em Ciências e } \\
\text { em Matemática, Geografia. }\end{array}$ \\
\hline
\end{tabular}

FONTE: Os autores (2020).

O trabalho de Freitas (1997) investiga os conhecimentos do "saber-fazer" dos moradores de determinada localidade, destaca que para se utilizar o conhecimento dos alunos em sala de aula, para propiciar uma apropriação com significado do conhecimento institucional, é necessário o envolvimento do pesquisador, do professor, dos alunos e da comunidade de forma integrada e inter-relacionada. Oliveira (2017) realiza sua pesquisa a partir de consulta a fontes orais, mediante entrevistas com cinco professores que participaram do processo de organização, elaboração, construção, formação continuada, e implementação da Proposta Pedagógica das Escolas das Ilhas do Litoral Paranaense. Destaca que as escolas das ilhas, devido às características geográficas e históricas da região, bem como dos modos de vida de suas populações, apresentam uma realidade diversa da realidade das escolas do continente. A pesquisa realizada por Farias (2018) propôs compreender e potencializar o ensino de geografia em escolas ribeirinhas, a partir do contexto amazônico e a relação/interação com o lugar e com o mundo como referência na construção do conhecimento. Analisa se a proposta curricular e o livro didático contemplam, orientam e possibilitam o ensino de geografia, a partir do contexto amazônico e a relação/interação com o lugar e com o mundo.

Dando continuidade, apresenta-se uma dissertação resultante da busca a partir do descritor "Educação Ribeirinha".

Quadro 6 - Pesquisas localizadas a partir do descritor "Educação Ribeirinha" que tem aderência com a pesquisa matriz

\begin{tabular}{|c|c|c|}
\hline Autoras & Instituição & Programa de Pós-Graduação \\
\hline Pinheiro (2009) & UFPA & Educação \\
\hline \multicolumn{2}{|c|}{ FONTE: Os autores (2020). }
\end{tabular}

A pesquisa de Pinheiro (2009) investiga o currículo e seus significados para os sujeitos de uma escola ribeirinha multisseriada. Analisa como se define e se materializa o currículo na escola, identificando quais significados são atribuídos ao currículo escolar pelos alunos, pais, comunitários e a professora. Evidencia que a educação ribeirinha precisa ser valorizada enquanto espaço de construção do conhecimento, a partir da valorização dos saberes culturais ribeirinhos, despertando-os para uma leitura de mundo e para construção de novos sujeitos políticos e sociais sintonizados com a sua territorialidade e identidade cultural. 
$\mathrm{Na}$ base de dados pesquisada encontraram-se outros trabalhos que provavelmente contribuiriam com as análises sobre o tema, porém não foi possível o acesso aos seus resumos, devido a não disponibilidade do formato digital.

Seguindo a descrição das pesquisas, apresentam-se os principais trabalhos oriundos do descritor "Escola Ribeirinha", sendo oito trabalhos, representados por duas teses e seis dissertações.

Quadro 7 - Pesquisas localizadas a partir do descritor "Escola Ribeirinha" que tem aderência com a pesquisa matriz

\begin{tabular}{|c|c|c|}
\hline Autoras(es) & Instituições & Programas de Pós-Graduação \\
\hline Victória (2008), Pinheiro $^{2}$ & & \\
(2009), Ferreira ${ }^{3}(2010)$, & UFAM, UFPA, UFAM, & Educação \\
Vasconcelos (2010), Lima & UFPel, UNOESTE, UEPA & \\
(2011), Silva (2015), Oliveira & & \\
(2016), Pereira (2016). & & \\
\hline
\end{tabular}

FONTE: Os autores (2020).

A investigação de Vasconcelos (2010) analisa como a prática pedagógica docente funciona como mediadora no processo de construção da identidade cultural de estudantes ribeirinhos. Os resultados da pesquisa demonstraram o desenvolvimento de práticas pedagógicas que contribuem com a construção da identidade cultural dos estudantes rurais/ribeirinho. Lima (2011) investiga a maneira como o currículo de uma escola ribeirinha se relaciona com os saberes culturais do meio onde se encontra. Evidencia que o currículo desenvolvido na escola investigada estabelece uma relação de aproximação com os saberes culturais de ribeirinhos da comunidade. A pesquisa de Oliveira (2016) avalia a participação da comunidade escolar ribeirinha nos encontros de preparação para a construção do projeto educativo escolar. Afirma que a escola teve a oportunidade de refletir sobre a sua prática pedagógica, a importância da participação efetiva da família e, sobretudo, repensar o processo de construção e/ou apropriação do conhecimento.

A seguir as pesquisas oriundas do descritor "Guaraqueçaba", com três trabalhos, dos quais uma tese e duas dissertações.

Quadro 8 - Pesquisas localizadas a partir do descritor "Escola Guaraqueçaba" que tem aderência com a pesquisa matriz

\begin{tabular}{|c|c|c|}
\hline Autoras & Instituições & Programas de Pós-Graduação \\
\hline $\begin{array}{c}\text { Duarte }(2013 ; 2018), \\
\text { Barbosa }(2014) .\end{array}$ & UDESC, UFPR, UFF. & $\begin{array}{c}\text { Planejamento Territorial e } \\
\text { Desenvolvimento Socioambiental, } \\
\text { Geografia. }\end{array}$ \\
\hline
\end{tabular}

FONTE: Os autores (2020).

\footnotetext{
${ }^{2}$ Consta no descritor "Educação Ribeirinha".

${ }^{3}$ Consta no descritor "Escola Rural".
} 
A pesquisa de Duarte (2013) investiga os conflitos territoriais decorrentes do estabelecimento do Parque Nacional do Superagui em um território tradicionalmente ocupado no município de Guaraqueçaba - PR. Os conflitos são decorrentes da sobreposição de interesses de diferentes agentes em um mesmo espaço. Defende que a luta das comunidades tradicionais e a formação das identidades locais são legítimas, mas é preciso que os sujeitos envolvidos nesta luta estejam atentos à pedagogia da hegemonia imbuída nos discursos de algumas organizações não-governamentais, bem como em políticas públicas.

O trabalho de Barbosa (2014) trata da emergência de Povos e Comunidades Tradicionais no cenário das lutas sociais no Brasil, como um processo de emergência de "novos" sujeitos sociais conformando identidades coletivas e territoriais, que afirmam sua identidade e diferença na luta pelo território, geralmente marcados por conflitos decorrentes do avanço do capitalismo espoliatório e, concomitantemente, marcado pelo enfrentamento/resistência dessas comunidades tradicionais em defesa de seus territórios.

Duarte (2018) versa sobre um contexto de conflito territorial decorrente da instauração de Unidades de Conservação restritivas em territórios tradicionalmente ocupados por pescadores(as) artesanais e caiçaras no município de Guaraqueçaba-PR, analisa a luta pelo território tradicional e constata que a participação popular vinha sendo acionada com o fim de legitimar processos de gestão territorial dos quais pescadores e caiçaras discordavam ou desconheciam.

Devido ao contexto e à relação entre os povos das águas e o mundo rural, apresentamse pesquisas realizadas nas Casas Familiares Rurais localizadas nas águas, no mar. Estas não foram identificadas a partir dos descritores utilizados na busca na base de dados da CAPES, mas por meio da leitura de outros trabalhos sobre as escolas rurais e escolas do campo.

Quadro 9 - Pesquisas que tem aderência com a pesquisa matriz, localizadas a partir de leituras sobre casas familiares do mar

\begin{tabular}{|c|c|c|}
\hline Autoras & Instituições & Programas de Pós-Graduação \\
\hline $\begin{array}{c}\text { Corrêa (2008), Pezarico } \\
\text { (2014). }\end{array}$ & UFSC, UTFPR. & $\begin{array}{c}\text { Educação Científica e Tecnológica, } \\
\text { Tecnologia. }\end{array}$ \\
\hline
\end{tabular}

FONTE: Os autores (2020).

Corrêa (2008) investiga "uma escola diferente" no estado de Santa Catarina, localizada em uma comunidade com predominância da pesca artesanal. Destaca que este tipo de escola contribui com o desenvolvimento local por meio de atividades inseridas no contexto de comunidades litorâneas e representando um processo inovador de formação escolar dos jovens. Indica na sua pesquisa que no Brasil existem outras escolas do mar na Bahia, Espírito Santo, Ceará. Pezarico (2014) pesquisa as relações estabelecidas entre o objeto "Casa Familiar”, a terra 
e o mar como laboratórios, espaços técnicos concretos e simbólicos no contexto da Pedagogia da Alternância. O estudo analisa processos de apropriação técnica no contexto da Pedagogia da Alternância, a partir das interações entre espaços técnicos e objetos, vivenciadas em nove Casas Familiares Rurais e uma Casa Familiar do Mar, localizadas na região Sul do Brasil.

Concluindo a apresentação das pesquisas, destacam-se as realizadas no contexto do litoral do Paraná, porém não foram identificadas com os descritores utilizados na busca na base de dados da CAPES, mas por meio da leitura de outros trabalhos sobre a realidade pesquisada.

Quadro 10 - Pesquisas que tem aderência com a pesquisa matriz, localizadas a partir de leituras sobre o contexto do litoral do Paraná

\begin{tabular}{|c|c|c|}
\hline Autoras & Instituições & Programas de Pós-Graduação \\
\hline $\begin{array}{c}\text { Cunha (2007), Cunha (2010), } \\
\text { Moura (2016), Andreoli } \\
(2016) .\end{array}$ & $\begin{array}{c}\text { Educação, Meio Ambiente e } \\
\text { Desenvolvimento, } \\
\text { Desenvolvimento Territorial } \\
\text { Sustentável. }\end{array}$ \\
\hline
\end{tabular}

FONTE: Os autores (2020).

Cunha (2007) investiga como ordens e desordens socioambientais se manifestam em dinâmicas pesqueiras da porção central da costa paranaense, privilegiando o conhecimento tradicional do pescador artesanal. Procura mostrar que a inter-relação entre pescador e mar é marcada, concomitantemente, por movimentos ordenados e desordenados, seja em sua dinâmica interna, seja em sua dinâmica externa. O estudo realizado por Moura (2016) trata do tema de povos e comunidades tradicionais e seus territórios, especificamente sobre pescadores artesanais, que possuem uma dinâmica própria de constituição de sua territorialidade baseada em práticas de uso comum dos recursos naturais.

A investigação de Cunha (2010), realizada em um campo empírico semelhante ao qual nos inserimos, isto é, em uma comunidade localizada em uma ilha do litoral paranaense, assume a etnografia como abordagem metodológica e discute a educação escolar na relação com a comunidade, elementos que se aproximam com nosso trabalho e nos ajudam a avançar nas compreensões da educação na realidade das ilhas. A autora salienta que "é preciso revigorar a discussão sobre os povos ribeirinhos e ilhéus [...]. Novas pesquisas sobre práticas educativas inspiradas na educação do campo, nesta região, considerando seu papel na sociedade, fazem-se necessárias." (CUNHA, 2010, p. 160). No seu estudo busca perceber a relação entre a escola e a comunidade local, definindo como objetivo geral analisar a relação existente entre a educação escolar e a vida na Vila de Ilha Rasa, em Guaraqueçaba-PR.

A pesquisa de Andreoli (2016) analisa quais são as relações entre a Educação Ambiental, o currículo e o desenvolvimento comunitário local, a partir da discussão sobre a educação e a formação humana como elementos de transformação social frente a crise 
socioambiental que se apresenta. Destaca-se que, de modo geral, as pesquisas apresentadas neste levantamento da produção de teses e dissertações do banco de dados da CAPES demonstram uma diversidade de preocupações em relação à vida dos povos que vivem e trabalham em comunidades localizadas no campo, nas águas e florestas.

Percebe-se, a partir das leituras realizadas, a busca de processos de pesquisa para além do campo da educação, em sua maioria apresentando análises articuladas com os aspectos culturais, sociais, políticos e econômicos, vislumbrando um olhar a partir da totalidade. $\mathrm{O}$ expressivo número de trabalhos encontrados, a partir dos descritores definidos, confirma o avanço de pesquisas em um campo fértil de conhecimentos a serem desvelados e revelados, que anunciam e denunciam.

\section{Resultados e análises: diálogos com as pesquisas}

A partir da revisão de literatura, pode-se afirmar que o diálogo com os trabalhos contribuiu significativamente com novas compreensões referentes à Educação do Campo, visto as aproximações com as questões discutidas na pesquisa de doutorado que originou este texto. Merece especial destaque os trabalhos de Mendes (2009; 2017), na investigação sobre a especificidade da Educação e Escola do Campo, Moura (2009) nas discussões sobre uma Educação do Campo que respeite o lugar e os saberes da comunidade escolar e Vieira (2018), que desenvolveu um estudo etnográfico em uma escola do campo em assentamento.

As pesquisas realizadas a partir da realidade Amazônica trouxeram outro olhar, isto é, a importância do contexto dos povos das águas e das florestas no entendimento da especificidade da escola do campo neste território, de modo especial às pesquisas de Cristo (2007), Ferraz (2010), Ferreira (2010), Pinheiro (2009) e Lima (2011), todas significativas para o entendimento das singularidades desta realidade. Os trabalhos de Freitas (1997), Oliveira (2017), Farias (2018), Corrêa (2008), Pezarico (2014), sobre o contexto das escolas relacionadas às ilhas ou ao mar, mostram o quão ainda é desafiante realizar práticas educativas condizentes com a realidade dos sujeitos, contudo, demonstraram a importância da educação e da escola para as comunidades.

Evidenciam-se também as pesquisas voltadas a questões sobre o território de Guaraqueçaba, realizando seus estudos a partir das análises dos conflitos territoriais e ambientais enfrentados pelas comunidades tradicionais no seu cotidiano. Destacam-se os estudos de Duarte $(2013 ; 2018)$ e Barbosa (2014), as pesquisadoras sugerem a continuidade de um percurso que já vem sendo realizado, com a luta pelos direitos individuais e coletivos destas comunidades. As quais têm como um dos seus maiores obstáculos o próprio Estado, o qual 
deveria garantir o que minimamente se preconiza nas legislações que tratam dos povos e comunidades tradicionais no Brasil. Pesquisas realizadas no contexto do litoral do Paraná, como as de Cunha (2007), Cunha (2010), Moura (2016) e Andreoli (2016) indicam elementos importantes que contribuíram nas problematizações relacionadas às práticas realizadas nas comunidades de pescadoras(es) artesanais e caiçaras e o papel da escola no diálogo com os sujeitos que produzem estes territórios tradicionalmente ocupados.

Cunha (2007), ao discutir os elementos da cosmovisão do pescador artesanal, apresenta questões relativas ao conhecimento tradicional destes sujeitos, que também são utilizados nas suas atividades de trabalho, no pescado. Moura (2016) ao investigar as práticas tradicionais de uma comunidade formada por pescadores e pescadoras artesanais e caiçaras, mostra a importância destas práticas no processo de territorialidade da própria comunidade. Demonstra que os conhecimentos tradicionais presentes no cotidiano são a expressão da dinâmica do modo de vida destes povos. As análises destes dois pesquisadores contribuem para a reflexão sobre a relação entre o conhecimento tradicional e o conhecimento científico, bem como trazem elementos que constituem o modo de vida destas comunidades.

A questão que orienta a pesquisa de Cunha (2010), “como ocorre à educação escolar na ilha e qual a relação existente entre o mundo da vida e a prática pedagógica nos anos iniciais?", tem parte das discussões mediadas pelo seguinte questionamento: "há um vínculo entre o mundo da escola e o mundo da Ilha?". Apontando elementos a serem observados, de modo a avançar no olhar para as comunidades situadas nas ilhas. Evidenciando como a comunidade se relaciona (ou não) de forma integrada com a escola, vista a consolidação das instituições escolares presentes na comunidade.

O estudo de Andreoli (2016) discute educação e formação humana como meios de transformação social, considerando a educação ambiental, o currículo e o desenvolvimento comunitário local como elementos importantes neste processo. Ao enfatizar a dimensão comunitária do campo empírico da sua pesquisa, aponta questões sobre a relação entre escola e comunidade, fortalecendo a importância de problematizar a relação entre os sujeitos e o território, este como meio de resistência das comunidades tradicionais. As reflexões da pesquisadora contribuíram para visualizar os possíveis significados da escola para a comunidade, evidenciando que o desenvolvimento comunitário também passa pela escola, a qual é fundamental para a formação dos sujeitos do campo que vivem e trabalham nas ilhas.

Neste sentido, as pesquisas realizadas no contexto do litoral paranaense contribuem significativamente para ampliar a análise conjuntural e estrutural que se manifestam nas políticas, mais delimitadamente no campo educacional, efetivadas na última década no estado 
do Paraná. São governos (Beto Richa e Ratinho Júnior), conduzido por grupos políticos alinhados a uma política neoliberal, de direita, baseados na lógica economicista da educação, tem efetivado políticas de desmonte das escolas públicas estaduais, o que também se percebe em muitos gestores municipais. No contexto do campo, existe um agravante, representado pelo fechamento das escolas, cuja estratégia tem sido a diminuição de turmas e a não oferta de vagas para determinados anos de ensino. Contraditoriamente, também existe no Estado organizações populares e sociais, como a Articulação Paranaense por uma Educação do Campo, das Águas e das Florestas (APEC) que faz o enfrentamento constante pela garantia e avanços dos direitos dos sujeitos que vivem e trabalham nestas realidades ameaçadas e atacadas por políticas neoliberais de extermínio das formas de vida destes povos.

A situação de precariedade ocorre como resultado de decisões políticas dos "gestores", que manipulam as comunidades, com falsas promessas de que a escola da cidade é melhor, de que haverá mais dias de aulas, melhoria de estradas rurais, melhores professores(as), entre outras falácias. É visto que o contexto precário das condições de vida no campo, nas águas e nas florestas passa pelo aspecto econômico, social e político e consequentemente reflete-se na dimensão educacional. Esta compreensão, de uma escola que, limitadamente, somente ensine a ler e escrever passa por uma questão ideológica, construída socialmente por um projeto de educação hegemônico. Esse projeto constrói o significado de uma escola precarizada, atrasada para as comunidades camponesas, pesqueiras, quilombolas, indígenas. Contundo é preciso pensar a escola a partir das reflexões de Cunha (2010), que apontam, em relação a uma educação vinculada com a vida de quem mora na ilha, que é fundamental uma aprendizagem, educação articulada com os hábitos já existentes na comunidade, que a educação tenha relações com o cotidiano das ilhas, a educação escolar influencia e é influenciada pela vida na ilha (CUNHA, 2010).

Findando esta seção de apresentação, análise e descrição das pesquisas, conclui-se que nas discussões realizadas pelas(os) autoras(es), são evidenciadas a existência de uma diversidade de preocupações em relação à vida dos povos que vivem e trabalham em comunidades localizadas no campo, nas águas e nas florestas. Percebe-se a partir das leituras realizadas, a busca de processos de pesquisa para além do campo da educação, em sua maioria apresentando análises articuladas com outros aspectos e segmentos da sociedade para além da educação. O expressivo número de trabalhos encontrados, a partir dos descritores definidos, demonstra o avanço de pesquisas na Educação do Campo. 


\section{Considerações Finais}

O conhecimento das pesquisas em Educação do Campo enseja a percepção de lacunas, limites, avanços e desafios deste domínio de investigação em educação. A revisão bibliográfica contribui no processo de identificar o que já foi produzido em determinado campo do conhecimento, neste caso a Educação do Campo, para que o(a) pesquisador(a) com um olhar crítico em relação à ciência possa propor outras pesquisas, no sentido de contribuir com o avanço do conhecimento em determinado campo.

A importância dos trabalhos expostos é evidente, bem como a lacuna de pesquisas que dialoguem com a realidade das comunidades que vivem e trabalham nos territórios tradicionalmente ocupados no contexto das ilhas do litoral brasileiro, principalmente no que se refere à educação. As pesquisas realizadas no contexto ribeirinho também contribuíram, visto que, como no caso das ilhas do litoral paranaense, estas populações estão inseridas na realidade da água e da floresta e historicamente resistem às diversas formas de violência e expulsão vivenciadas cotidianamente em seus territórios.

Nesses contextos específicos das populações do campo, das águas e das florestas, a escola tem se mostrado, em muitos casos, restrita ao lugar do aprender a ler e escrever. No entanto, há que se superar a visão dominante da escola nestas comunidades, a percepção de uma escola atrasada, com professores(as) não suficientemente qualificados, bem como as visões romantizadas destes territórios. No entanto, em muitas pesquisas apresentadas neste estudo, evidenciaram-se articulações possíveis entre a comunidade e a escola, no sentido de promover ações escolares que dialogam com a realidade dos territórios e das demandas dos sujeitos. Neste sentido, defende-se que a escola também deve ensejar a socialização, a compreensão da diversidade cultural, a apropriação de conhecimentos universais, a valorização dos conhecimentos tradicionais e ancestrais, evitando que o cotidiano da vida seja deslocado da escola, na expectativa de ir além do ler e escrever, buscando produzir uma educação emancipadora.

Enquanto cenário específico da Educação do Campo, no contexto das ilhas, entendese ser necessário problematizar a existência ou não do diálogo entre terra e mar, entre os sujeitos que constituem as comunidades do campo, das águas e das florestas e suas relações em contexto muitas vezes precário de existência. Pensar em estratégias de superação, enquanto sujeitos comprometidos com a emancipação e com poder de transformação, a partir da tomada de consciência de sua realidade, torna-se um possível caminho para sair das condições de opressão e marginalidade. 
É urgente a articulação e diálogo para o fortalecimento e busca da unidade na diversidade da classe trabalhadora, isto é, entre as(os) trabalhadoras(es) do campo, das águas, das florestas, das cidades, das periferias. Essa articulação é possível a partir da centralidade do diálogo em prol da construção de relações sociais mais autênticas e justas, que emerge da referência constante à realidade destas populações e às formas como elas constroem esta realidade. Vislumbra-se, dessa forma, um trabalho ao longo do processo pedagógico de transformação social, sempre em respeito à relação entre conhecimento e política, entre educação e movimentos sociais do campo, que considere as dimensões fundamentais da vida dos sujeitos.

Diante do exposto, salienta-se também a importância da continuidade de estudos que fortaleçam o movimento de produção de conhecimentos em uma realidade específica, ou seja, a Educação do Campo, território também produtor de conhecimento, que se vê desafiado a produzir novas pesquisas comprometidas com a transformação social.

\section{REFERÊNCIAS}

ALBUQUERQUE, Ariane Berg. Vozes desencontradas: a percepção dos estudantes do campo e da escola no campo. 2017. 147 f. Dissertação (Mestrado em Educação) Universidade Federal do Paraná, Curitiba, 2017.

ANDREOLI, Vanessa Marion. A educação ambiental no contexto dos colégios estaduais da Ilha do Mel/PR: currículo, ação docente e desenvolvimento comunitário local. 2016. 371 f. Tese (Doutorado em Educação) - Universidade Federal do Paraná, Curitiba, 2016.

ARAÚJO, Jefferson Flora Santos de. O Currículo e as práticas pedagógicas (des)contextualizadas da Escola no Campo do Semiárido Paraibano. 2017. $113 \mathrm{f}$. Dissertação (Mestrado Profissional em Formação de Professores) - Universidade Estadual da Paraíba, Campina Grande, 2017.

ARAÚJO, Rafaela Santos. Atos curriculares na escola no campo: proposta para uma educação contextualizada. 2017.151 f. Dissertação (Mestrado em Educação e Diversidade) Universidade do Estado da Bahia, Jacobina, 2017.

ARROYO, Miguel Gonzalez. A educação básica e o movimento social do campo. Brasília, DF: Articulação Nacional por uma Educação Básica do Campo, 1999.

BARBOSA, Aline Miranda. Povos e comunidades tradicionais em luta pelo território: intersecções e tensões entre a questão agrária e a questão ambiental. 2014. 139 f. Dissertação (Mestrado em Geografia) - Universidade Federal Fluminense, Niterói, 2014.

BENFICA, Welessandra Aparecida. A escola rural na década de 90: expectativas e significados da experiência escolar para os alunos e suas famílias. 2006. 161 f. Dissertação 
(Mestrado em Educação) - Pontifícia Universidade Católica de Minas Gerais, Belo Horizonte, 2006.

BOITO, Crisliane. Práticas pedagógicas para infâncias no/do campo: experiências de uma escola em interlocução com crianças, famílias e comunidade. 2017. 184 f. Dissertação (Mestrado em Educação) - Universidade Federal do Rio Grande do Sul, Porto Alegre, 2017.

BUFREM, Leilah Santiago. Informação, conhecimento e verdade: discussões contemporâneas. Brazilian Journal of Information Studies: Research Trends. v. 10, n. 2 , p.89-102, 2016.

CALDART, Roseli Salete. A Escola do Campo em Movimento. In: ARROYO, Miguel Gonzalez et al. Por uma educação do campo. 2. ed. Petrópolis: Vozes, 2004.

CORRÊA, Cirlei Marieta de Sena. Casa familiar do mar em Santa Catarina: complexidade de uma prática educativa. 2008. 142 f. Tese (Doutorado em Educação Científica e Tecnológica) - Universidade Federal de Santa Catarina, Florianópolis, 2008.

CORREIA, Elis Santos. $O$ fechamento das escolas do campo em Sergipe: territórios em disputa (2007-2015). 2018. 210 f. Dissertação (Mestrado em Educação) - Universidade Federal de Sergipe, São Cristóvão, 2018.

CRISTO, Ana Cláudia Peixoto de. Cartografias da educação na Amazônia rural ribeirinha: estudos de currículo imagens, saberes e identidades em uma escola do município de Breves/ PA. 2007. 165 f. Dissertação (Mestrado em Educação) - Universidade Federal do Pará, Belém, 2007.

CRUZ, Elenciria Oliveira da. A escola no campo: ouvindo crianças e adolescentes da zona rural do município de Viçosa, MG. 2013.233 f. Dissertação (Mestrado em Economia Domestica) - Universidade Federal de Viçosa,Viçosa, 2013.

CUNHA, Lúcia Helena de Oliveira. Significados múltiplos das águas. In: DIEGUES, Antonio Carlos (Org.). A imagem das águas. São Paulo: Hucitec, 2000. p. 15-26.

CUNHA, Lúcia Helena de Oliveira. Ordens e desordens socioambientais: saberes tradicionais em dinâmicas pesqueiras da costa paranaense. 2007. 204 f. Tese (Doutorado em Meio Ambiente e Desenvolvimento) - Universidade Federal do Paraná, Curitiba, 2007.

CUNHA, Mariângela Hoog. Um "sítio" no mar: estudo da educação escolar na vila de Ilha Rasa /PR. 2010. 175 f. Dissertação (Mestrado em Educação) - Universidade Tuiuti do Paraná, Curitiba, 2010.

DUARTE, Leticia Ayumi. Argonautas do Superagui: identidade, território e conflito em um parque nacional brasileiro. 2013. 211 f. Dissertação (Mestrado Profissional em Planejamento Territorial e Desenvolvimento Socio-Ambiental) - Universidade do Estado de Santa Catarina, Florianópolis, 2013.

DUARTE, Leticia Ayumi. "Resistir e retomar, nossa terra e nosso mar": os comuns como planejamento e gestão territoriais subversivos em Guaraqueçaba - PR. 2018. 447 f. Tese

(Doutorado em Geografia) - Universidade Federal do Paraná, Curitiba, 2018. 
FARIAS, Rosana Torrinha Silva de. Ensino de geografia nas escolas das ilhas Queimadas/PA: o lugar ribeirinho no contexto amazônico. 2018. 237 f. Tese (Doutorado em Geografia) - Universidade Federal de Goiás, Goiânia, 2018.

FERRAZ, Lidia Rochedo. O cotidiano de uma escola rural ribeirinha na Amazônia: práticas e saberes na relação escola-comunidade. 2010. 256 f. Tese (Doutorado em Psicologia) - Universidade de São Paulo, Ribeirão Preto, 2010.

FERREIRA, Jarliane da Silva. E o rio, entra na escola? Cotidiano de uma escola ribeirinha no município de Benjamin Constant/AM e os desafios da formação de seus professores. 2010. 136 f. Dissertação (Mestrado em Educação) - Universidade Federal do Amazonas, Manaus, 2010.

FREITAS, Franceli Fernandes de. A formação de professores da Ilha De Maré-Bahia. 1997.120 f. Dissertação (Mestrado em Educação) - Universidade Estadual de Campinas, Campinas, 1997.

GUGELMIN, Gloria Maria Mendes Curvo. Educação do campo: uma análise do diálogo entre saber escolar e saber local no contexto do programa ProJovem. 2014. 88 f. Dissertação (Mestrado em Educação) - Universidade Federal de Mato Grosso, Cuiabá, 2014.

KLEIN, Sonia Francisco. Educação do campo: um estudo sobre cultura e currículo na escola municipal de ensino fundamental Crubixá - Alfredo Chaves - Espírito Santo. 2013. 228 f. Dissertação (Mestrado em Educação) - Universidade Federal do Espírito Santo, Vitória, 2013.

KOLLING, Edgar Jorge; NERY, Israel José; MOLINA, Mônica Castagna. Por uma educação básica do campo. v. 1. Brasília: Fundação Universidade de Brasília, 1999.

LIMA, Eloisa Aparecida Cerino Rosa. Educação do campo: rompendo cercas e disputando territórios - estudo das práticas do assentamento Roseli Nunes e escola Madre Cristina. 2017. 173 f. Dissertação (Mestrado em Desenvolvimento Territorial na América Latina e Caribe) Universidade Estadual Paulista Júlio de Mesquita Filho, São Paulo, 2017.

LIMA, Fabiana Ribeiro Souza. Cotidiano em uma escola rural: representações de uma comunidade escolar. 2008.120 f. (Mestrado Em Extensão Rural) - Universidade Federal de Viçosa, Viçosa, 2008.

LIMA, Lais Alcantara Rios. O significado das escolas rurais multisseriadas no contexto do município de São Gonçalo dos Campos-BA. 2015. 133 f. Dissertação (Mestrado em Educação) - Universidade Estadual de Feira de Santana, Feira de Santana, 2015.

LIMA, Maristela Rocha. Sou rural, sou gente, tenho identidade: cultura, cotidiano e narrativas de alunos de escola rural. 2018. 215 f. Dissertação (Mestrado em Educação) Universidade do Estado da Bahia, Salvador, 2018.

LIMA, Natamias Lopes de. Saberes culturais e modos de vida de ribeirinhos e sua relação com o currículo escolar: um estudo no município de Breves/PA. 2011. 159 f. Dissertação (Mestrado em Educação) - Universidade Federal do Pará, Belém, 2011. 
MELO, Raimunda Alves. Prática docente na escola do campo: diálogos sobre a articulação dos conhecimentos escolares aos saberes da cultura camponesa. 2014. 162 f. Dissertação (Mestrado em Educação) - Universidade Federal do Piauí, Teresina, 2014.

MENDES, Marciane Maria. A escola do campo e seu significado: o ponto de vista de professores e professoras da rede estadual de educação do Paraná. 2009. 171 f. Dissertação (Mestrado em Educação) - Universidade Federal do Paraná, Curitiba, 2009.

MENDES, Marciane Maria. Especificidades da educação e da escola do campo: documentos oficiais e produção bibliográfica em análise (1996-2016). 2017. 230 f. Tese (Doutorado Em Educação) - Universidade Federal do Paraná, Curitiba, 2017.

MOLINA, Mônica Castagna; ANTUNES-ROCHA, Maria Isabel; MARTINS, Maria de Fátima Almeida. A produção do conhecimento na licenciatura em Educação do Campo: desafios e possibilidades para o fortalecimento da educação do campo. Rev. Bras. Educ. v. 24, p. 1-30, out. 2019.

MOURA, Edinara Alves de. Lugar, saber social e educação no campo: o caso da escola municipal de ensino fundamental José Paim de Oliveira - Distrito de São Valentim, Santa Maria, RS. 2099. 198 f. Dissertação (Mestrado em Geografia) - Universidade Federal de Santa Maria, Santa Maria, 2009.

MOURA, Ezequiel Antonio de. A coroazinha da Ilha do Mel: territorialidade de uma comunidade tradicional de pescadores (as) artesanais na Ponta Oeste, Paranaguá - PR. 2016. 140 f. Dissertação (Mestrado em Desenvolvimento Territorial Sustentável) - Universidade Federal do Paraná, Matinhos, 2016.

NAHIRNE, Ana Paula. O cotidiano de uma escola do campo e a prática social de ensino da matemática na concepção da comunidade escolar. 2017. 170 f. Dissertação (Mestrado em Educação) - Universidade Estadual do Oeste do Paraná, Cascavel, 2017.

OLIVEIRA, Anderson Martins. Proposta pedagógica das escolas das ilhas do litoral paranaense: narrativas de um processo de construção. 2017. $271 \mathrm{f}$. Dissertação (Mestrado em Educação em Ciências e em Matemática) - Universidade Federal do Paraná, Curitiba, 2017.

OLIVEIRA, Francisco Miguel da Silva de. Construção do projeto educativo escolar no contexto de uma escola ribeirinha marajoara: desafios para uma ação participativa. 2016. 113 f. Dissertação (Mestrado em Educação) - Universidade do Oeste Paulista, Presidente Prudente, 2016.

OLIVEIRA, Mara Rita Duarte. A escola rural da vila da paz: um ensaio etnográfico. 2003. 130 f. Dissertação (Mestrado em Agriculturas Amazônicas) - Universidade Federal do Pará, Belém, 2003.

PAULA, Adalberto Penha. Relações entre Educação do Campo e o território: significados da escola da/na ilha para uma comunidade tradicional de Guaraqueçaba no litoral do Paraná. 2019. 257 f. Tese (Doutorado em Educação) - Universidade Federal do Paraná, Curitiba, 2019. 
PEREIRA, Amarildo Nunes. Territorialidades da educação do campo na região sudoeste do Paraná na última década (2000-2010). 2003. 118 f. Dissertação (Mestrado em Geografia) - Universidade Estadual do Oeste do Paraná, Francisco Beltrão, 2003.

PEREIRA, Rosenildo da Costa. Saberes culturais e prática docente no contexto da escola ribeirinha. 2016. 184 f. Dissertação (Mestrado em Educação) - Universidade do Estado do Pará, Belém, 2016.

PEZARICO, Giovanna. A casa, a terra e o mar: os objetos e os espaços no contexto da pedagogia da alternância. 2014. $204 \mathrm{f}$. Tese (Doutorado em Tecnologia) - Universidade Tecnológica Federal do Paraná, Curitiba, 2014.

PINHEIRO, Maria do Socorro Dias. Currículo e seus significados para os sujeitos de uma escola ribeirinha, multisseriada no município de Cametá - Pará. 2009. 203 f. Dissertação (Mestrado em educação) - Universidade Federal do Pará, Belém, 2009.

QUEIROZ, Zuleide Fernandes de. A escola rural e a questão do saber: do saber universal ao saber construído pelo homem do campo. 1992. 190 f. Dissertação (Mestrado em Educação) - Universidade Federal do Ceará, Fortaleza, 1992.

REGO, Marcondes Batista do. O currículo na escola do campo e sua inter-relação com o mundo do trabalho. 2016. 116 f. Dissertação (Mestrado em Educação) - Universidade Estadual de Roraima e Instituto Federal de Educação, Ciência e Tecnologia de Roraima, Boa Vista, 2016.

REIS, Edmerson dos Santos. A contextualização dos conhecimentos e saberes escolares nos processos de reorientação curricular das escolas do campo. 2009. $318 \mathrm{f}$. Tese (Doutorado em Educação) - Universidade Federal da Bahia, Salvador, 2009.

RODRIGUES, Dilma Alves. O significado da escola rural revelado na trilha do trabalho. 1993. 203 f. Dissertação (Mestrado Em Educação) - Universidade Federal de Minas Gerais, Belo Horizonte, 1993.

RODRÍGUEZ, Inés Olivera. Relação juventude - escola frente aos processos excludentes: discutindo as experiências sociais e os sentidos da escolaridade em Chaquira, um caserio rural no litoral norte do Peru. 2008. 224 f. Dissertação (Mestrado em Educação) - Universidade Federal de Santa Catarina, Florianópolis, 2008.

SÁNCHEZ VÁSQUEZ, Adolfo. Filosofia da práxis. São Paulo: Expressão Popular, 2011.

SANTOS, Aparecido Lino dos. Educação do campo: discursos sobre currículo, identidades e culturas. 2015. 151 f. Dissertação (Mestrado em Educação) - Universidade Federal da Grande Dourados, Dourados, 2015.

SILVA, Andrea Natalia da. Currículo e práticas mono/multi/interculturais e a produção de identidades e diferenças na escola estadual do campo Nova Itamarati. 2014. $265 \mathrm{f}$. Tese (Doutorado em Educação) - Universidade Católica Dom Bosco, Campo Grande, 2014a. 
SILVA, Iorim Rodrigues da. Gestão democrática na educação do campo: o significado do projeto pedagógico na construção de ações e relações participativas. 2014. 146 f. Dissertação (Mestrado em Educação) - Universidade Federal de Mato Grosso, Rondonópolis, 2014b.

SILVA, Marcos Nicolau Santos Da. O território camponês como dimensão educativa: desafios e possibilidades da educação do campo e do ensinar-aprender geografia em GrajaúMA. 2018. 207 f. Tese (Doutorado em Geografia) - Universidade Federal de Minas Gerais, Belo Horizonte, 2018.

SILVA, Maria Aparecida Nascimento da. Currículo da escola ribeirinha na Amazônia e a produção da identidade cultural dos docentes e alunos das classes multisseriadas do ensino fundamental. 2015. 185 f. Tese (Doutorado em Educação) - Universidade Federal de Pelotas, Pelotas, 2015.

SILVEIRA, Vera Lucia Costa da. O entorno da escola rural Astrogildo Pereira da Costa como constitutivo da construção curricular da escola. 2009. 134 f. Dissertação (Mestrado em Educação) - Universidade Federal de Pelotas, Pelotas, 2009.

SOUZA, Edilma de. Entre cartografias e beiras: espaçostempos de crianças ribeirinhasamazônidas mato-grossenses. 2015. 158 f. Dissertação (Mestrado em Educação) Universidade do Estado de Mato Grosso, Cáceres, 2015.

SOUZA, Maria Antônia de. Educação e Movimentos Sociais do Campo: a produção do conhecimento no período de 1987 a 2015. 2. ed. Curitiba: UFPR, 2016.

TEODORO, Bruno Otávio. (Re) Conhecimentos gerais: a escola rural e os múltiplos saberes de um povo geralista, possibilidades e limitações de diálogo. 2010. 165 f. Dissertação (Mestrado em Educação) - Universidade de Brasília, Brasília, 2010.

UCHOA, Iraci Carvalho. Trabalho e educação do campo no contexto amazônico: um estudo em uma comunidade camponesa do médio Rio Solimões. 2018.133 f. Dissertação (Mestrado em Educação) - Universidade Federal do Amazonas, Manaus, 2018.

VASCONCELOS, Maria Eliane de Oliveira. Identidade cultural de estudantes rurais/ ribeirinhos a partir das práticas pedagógicas. 2010. 133 f. Dissertação (Mestrado em Educação) - Universidade Federal do Amazonas, Manaus, 2010.

VICTÓRIA, Cláudio Gomes da. Desafios do cotidiano na formação e práxis dos educadores de uma escola ribeirinha no município do Careiro desafios do cotidiano. 2008. 124 f. Dissertação (Mestrado em Educação) - Universidade Federal do Amazonas, Manaus, 2008.

VIEIRA, Edilaine Aparecida. Jovens, escolarização e livros didáticos: estudo etnográfico em uma escola de assentamento (SC). 2018. 256 f. Tese (Doutorado em Educação) Universidade Federal do Paraná, Curitiba, 2018.

ZIECH, Marcia Eliana. Educação do campo e a construção da identidade territorial do aluno da escola do campo do Distrito de Cândido Freire - Giruá (RS). 2017. $121 \mathrm{f}$. Dissertação (Mestrado em Educação) - Universidade Regional do Noroeste do Estado do Rio Grande do Sul, Ijuí, 2017. 


\section{SOBRE OS AUTORES:}

\section{Adalberto Penha de Paula}

Doutor em Educação pela Universidade Federal do Paraná (UFPR). Professor na Licenciatura em Educação do Campo - Ciências da Natureza da Universidade Federal do Paraná (UFPR) no Setor Litoral - Matinhos - Paraná. E-mail: adalbertoppenha@gmail.com

(iD https://orcid.org/0000-0002-9906-3989

\section{Leilah Santiago Bufrem}

Doutora em Ciência da Comunicação pela Universidade de São Paulo (USP). Professora permanente no Programa de Pós-Graduação em Educação da Universidade Federal do Paraná (UFPR) - Curitiba - Paraná. E-mail: santiagobufrem@gmail.com

(iD https://orcid.org/0000-0002-3620-0632 